\title{
Using carbon isotopes to reconstruct fire and vegetation change history at a shrub encroached grassland in the Northern Chihuahuan Desert Junran $\mathrm{Li}^{1}$, Guan Wang ${ }^{2}$
}

${ }^{1}$ Department of Geosciences, The University of Tulsa, Tulsa, OK, 74104, USA, e-mail: junran@utulsa.edu

2 Department of Geosciences, The University of Tulsa, Tulsa, OK, 74104, USA, e-mail: guw647@utulsa.edu

Fire is a key ecological process affecting vegetation change, source and sink dynamics of sediment, and land cover in the terrestrial environment. Many studies have showed that the Chihuahuan Desert in the North America has experienced extensive woody shrub encroachment during the past 150 years, and fire suppression induced by human range management practices, such as grazing acts, is often considered as one of the probable drivers of this vegetation shift. The state of vegetation change and associated drivers before the large-scale livestock ranching in the $1850 \mathrm{~s}$ is largely speculate and direct, spatially explicit evidence is missing. Here we used stable $\left(\delta^{13} \mathrm{C}\right)$ and radiocarbon $\left(\delta^{14} \mathrm{C}\right)$ to investigate fire history and its coetaneous vegetation state at a grassland-shrubland transition zone in the northern Chihuahuan Desert, USA. Five study plots, representing change of vegetation from shrub-dominant to grass-dominant, were located. Three 1-m soil profiles were used in each study plot to obtain soil samples at various depth. Soil charcoal samples were collected and interpreted to determine the frequency and intensity of fires. The relative coverage of grass and shrub was estimated using $\delta^{13} \mathrm{C}$, aided by analysing the geochemical characteristics of charcoals in the soil samples. The corresponding ages of these samples were estimated using radiocarbon $\left(\delta^{14} \mathrm{C}\right)$ dating. Our results showed a stable fire frequency before 200 years ago, and a sudden increase in fire frequency in approximately 150 years ago, which is in agreement with the time when European settlers arrived in this region. We inferred it might be related to human setting fire to modify the landscape at that time. From then on, fire frequency gradually reduced, in accompany with the increased shrub biomass. The results suggested that fire suppression has favoured scattered shrubs rather than widespread grasses, which, combined with increased grass consumption by livestock grazing, contributed to vegetation shift from desert grasslands to shrub-grass mixed ecotones. 